\title{
PENYULUHAN PENTINGNYA PEMBERIAN ASI EKSKLUSIF DI WILAYAH KERJA PUSKESMAS MINAS UPA KOTA MAKASSAR
}

\author{
https://doi.org/10.33024/jkpm.v4i6.4214 \\ Sumarni Sikki ${ }^{*}$, Rismawati Simbung ${ }^{2}$ \\ 1-2 Fakultas Keperawatan dan Kebidanan Universitas Mega Resky \\ Disubmit: 18 April 2021 Diterima: 08 Juni 2021 Diterbitkan: 01 Desember 2021 \\ Email Korespondensi: sumarnimrm@gmail.com
}

\begin{abstract}
ABSTRAK
Dalam rangka menurunkan angka kesakitan dan kematian bayi, UNICEF dan WHO merekomendasikan sebaiknya bayi hanya disusui air susu ibu (ASI) selama paling sedikit 6 bulan, dan pemberian ASI dilanjutkan sampai bayi berumur dua tahun (WHO, 2018). Dewasa ini fenomena yang terjadi pada ibu melahirkan anak pertama mengalami masalah menyusui dengan ketidaklancaran keluarnya ASI. Selain itu ibu sering mengeluhkan bayinya sering menangis atau menolak menyusu, Puting lecet sehingga tidak memberikan ASI. Sehingga sering menyebabkan diambilnya keputusan untuk menghentikan menyusui. (Maliha, dkk, 2016). Tujuan pengabdian Masyarakat ini untuk memberikan informasi tentang pentinya pemberian ASI Eksklusif. Metode Pengabdian masyarakat ini yaitu dilakukan pre-test dan post- test pada 50 orang responden. Hasil olahan data menggunakan uji Paired Samples Test diperoleh ada peningkatan pengetahuan dari rata-rata nilai quisioner pre-test diperoleh nilai jawaban yang benar 58,88 setelah penyuluhan berubah menjadi 76,40 dengan nilai $\rho=0.000$ yang berarti terjadi peningkatan pengetahuan tentang pemberian ASI Ekslusif.
\end{abstract}

Kata Kunci: Penyuluhan, ASI, Eksklusif,

\begin{abstract}
In order to decrease the number morbidity and mortality infant, UNICEF and WHO recommend should babies only breastfed water milk mother (ASI) for the bit 6 moths, and the provision of breastfeeding be continued until the baby is aged two years (WHO, 2018). Adults have phenomena that occur in mother giving birth child first experienced trouble breast feeding with un normal release of ASI. In addition, mother often complain that their babies often cry or refuse to breastfeed, and the nipples are blistered so they don't give breast milk. Thus often causing taken the decision to stop breastfeeding (Maliha, et al, 2016). Community service goals this to provide information about the importance of exclusive service goals this to provide information about the importance of exclusive breastfeeding. Method devotion society is test by pre - test and post test at the 50 respondents. The processed using test paired samples test gained no increase in the knowledge of the average value quaternary pre - test obtained value of answer that is correct 58.88 after the counseling changed into 76.40 with the value $\rho=0.000$ which means that the case increase knowledge about the provision of breastfeeding exclusive.
\end{abstract}

Key Word : Counseling, Breast Milk, Exclusive 


\section{PENDAHULUAN}

Dalam rangka menurunkan angka kesakitan dan kematian bayi, UNICEF dan WHO merekomendasikan sebaiknya bayi hanya disusui air susu ibu (ASI) selama paling sedikit 6 bulan, dan pemberian ASI dilanjutkan sampai bayi berumur dua tahun. Agar ibu dapat mempertahankan ASI eksklusif selama 6 bulan, WHO merekomendasikan agar melakukan inisiasi menyusui dalam satu jam pertama kehidupan, bayi hanya menerima ASI tanpa tambahan makanan atau minuman, termasuk air, menyusui sesuai permintaan atau sesering yang diinginkan bayi, dan tidak menggunakan botol atau dot (Simanungkalit, 2018).

Sustainable Development Goals dalam The 2030 Agenda For Sustainable Development menargetkan pada tahun 2030 dapat mengurangi angkas kematian neonatal paling sedikit 12 per 1.000 kelahiran hidup dan kematian pada anak di bawah usia 5 tahun paling sedikit 25 per 1.000 kelahiran hidup. Hal tersebut dapat dicapai salah satunya dengan pemberian ASI eksklusif dilaksanakan dengan baik (Bahriyah et al., 2017)

Di Indonesia cakupan pemberian ASI eksklusif masih jauh dari target nasional sebesar $80 \%$. Hasil survey Demografis Kesehatan Indonesia (SDKI) tahun 2016 menunjukkan bahwa cakupan pemberian ASI ekslusif bayi 0-6 bulan hanya sebesar 42\% (Rosyid \& Sumarmi, 2017).

Data profil Kesehatan RI 2007 memperlihatkan pemberian ASI Eksklusif di Sulawesi Selatan adalah 3,36\% dengan durasi $\leq 5$ bulan dan 8,85\% dengan durasi 6 - 11 bulan bagi anak umur 2-4 tahun. (Akbulut, 2010) Adapun jumlah KN 1 di Puskesmas Minasaupa kota Makassar tahun 2015 (576), Tahun 2016 (520), Tahun 2017 (530), Tahun 2018 (470), Tahun 2019 (429) 2020 (479).(Badan PPSDM Kesehatan Informasi SDM Kesehatan Kementrian Kesehatan Republik Indonesia, 2020).

Fenomena yang terjadi pada ibu melahirkan anak pertama mengalami masalah menyusui dengan ketidaklancaran keluarnya ASI. Selain itu ibu sering mengeluhkan bayinya sering menangis atau menolak menyusun. Puting lecet sehingga tidak memberikan ASI. Sering diartikan bahwa ASInya tidak cukup atau ASInya tidak enak, sehingga sering menyebabkan diambilnya keputusan untuk menghentikan menyusui. (Dinas Kesehatan Kabupaten Semarang, 2015).

Chapman, (2010) yang menemukan terjadinya peningkatan angka dan lamanya pemberian ASI eksklusif, pada kelompok ibu menyusui dengan "Peer Counseling"(Annisa \& Naimah, 2012). Penelitian lainnya seperti Alex K, dkk. (2007) juga menemukan terjadinya perbedaan respon pemberian ASI eksklusif pada kelompok ibu yang diberi konseling dengan yang tidak diberi konseling (Anam et al., 2019).

Oleh karena itu, kami tertarik melakukan pengabdian masyarakat dengan tema pentingnya pemberian ASI Ekslusif di Wilayah kerja Puskesmas Minasa upa kota Makassar.

\section{MASALAH}

Alasan kami memilih tempat kegiatan karena Wilayah kerja Puskesmas minasa upa adalah daerah perkotaan dimana sebagaian besar penduduknya memiliki aktifitas yang padat, tercatat bahwa $59,9 \%$ bekerja di pemerintahan, $37,3 \%$ sebagai pedagang dan 3,8\% sebagai buruh bangunan. (Rama, 2017) sehingga secara status ekonomi masyarakat diwilayah kerja puskesmas minasa upa memiliki pilihan untuk memberikan susu formula 
sebagai pengganti ASI. Selain itu Pemahaman masyarakat tentang ASI Ekslusif masih sangat minim sehingga banyak masyarakat menganggap bahwa susu formula lebih baik dari pasi ASI. Tujuan khusus dari penyuluhan ini adalah peserta dapat mengerti dan memahami pentingnya pemberian ASI secara ekslusif mulai dari 0 - 6 bulan.

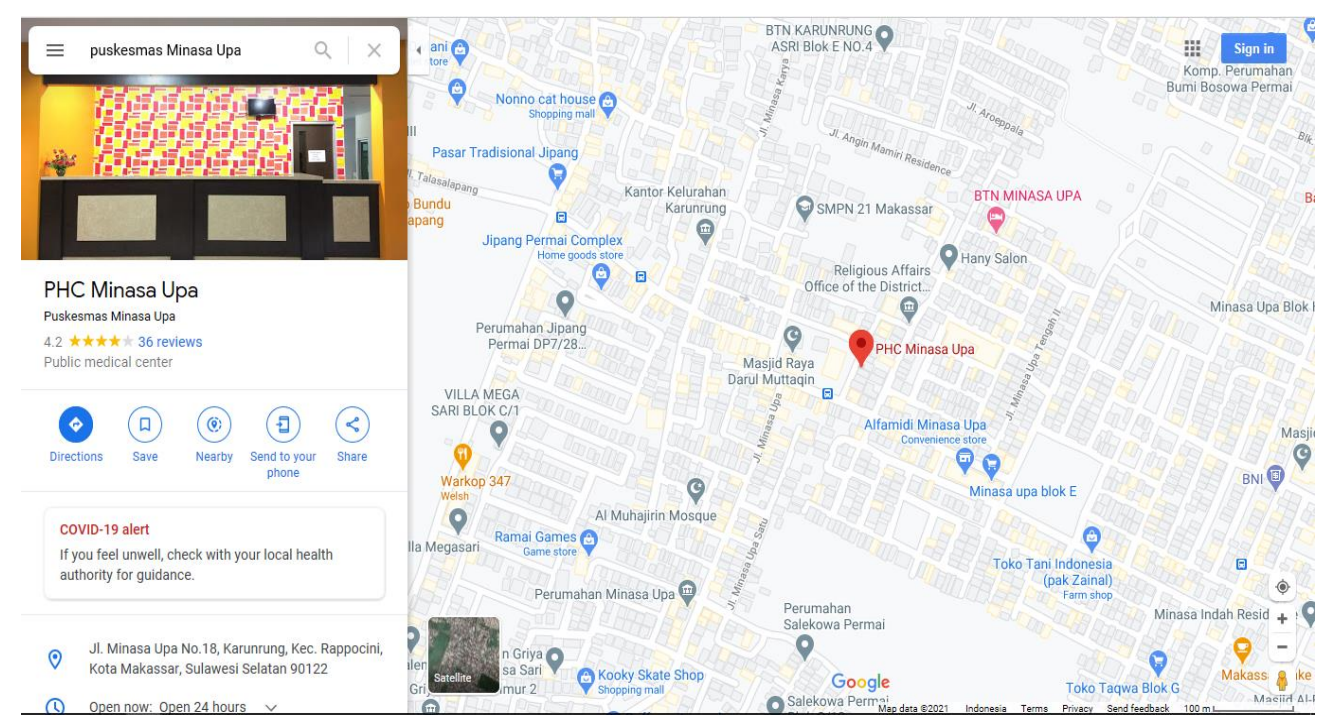

Gambar 2.1 Peta Lokasi Kegiatan Pengbdian Kepada Masyarakat

\section{METODE}

a. Tujuan Persiapan

Tahap persiapan dari kegiatan adalah pembuatan pre planning, persiapan penyajian leaflet, memasang LCD dan mengkoneksikannya dengan laptop kemudian mempersiapkan kuesioner pra test terkait pemahaman peserta penyuluhan. Persiapan ini dimulai dari pukul 08.00 wita sampai briefing panitia penyelenggara 08.30 wita pada tanggal 20 Desember 2020 di salah satu Posyandu yang menjadi wilayah kerja Puskesmas Minasa Upa kota Makassar.

b. Tahap pelaksanaan

Acara ini dilaksanakan dengan menyesuaikan jadwal posyandu puskesmas minasa upa. Setelah peserta berkumpul maka dilakukan pembukaan oleh MC acara tepat pada pukul 09.00 Wita, selanjutnya kuesioner pra tes dibagikan kepada peserta setelah semua peserta mengisi kuesioner dilanjutkan dengan pemberian materi penyuluhan pentingnya pemberian ASI Eksklusif.

c. Evaluasi

i. Struktur

Peserta yang hadir pada kegiatan berjumlah 50 orang dengan kemudian dilakukan pembagian kuesioner pra test. Pertanyaan berjumlah 20 butir dengan menggunakan bahasa yang mudah dipahami dan dimengerti.

ii. Proses

Pemberian materi berlangsung dari pukul 09.30 sampai 10.00 wita dilanjutkan pemberian kuesioner post tes. Kegiatan berjalan sesuai dengan jadwal yang telah direncanakan. 


\section{HASIL DAN PEMBAHASAN}

Kegiatan Penyuluhan ini dilaksanakan dengan jumlah Peserta sebanyak 50 orang. Dalam kegiatan pengabdian masyarakat ini dilaksanakan dengan membawakan materi terkait Komposisi ASI, manfaatnya, serta cara Pemberian ASI secara ekslusif pada bayi ibu. Hasil yang telah dilakukan dan dicapai pada pelaksanaan kegiatan PKM ini meliputi tahapan berikut:

a. Berkordinasi dengan bidan kordinasi di PKM minaasaupa

b. Melakukan pretest terkait pengetahuan ibu tentang komposisi ASI dan manfaatnya

c. Memberikan penyuluhan secara mandiri dengan menggunakan laflet

d. Menjelaskan kepada ibu tentang pengetahuan ASI dan manfaatnya

e. Melakukan posttest terkait pengetahuan ibu tentang komposisi ASI dan manfaatnya

Pada kegiatan ini dilakukan pre-test sebagai dasar pengetahuan awal dari peserta yang mengikuti kegiatan ini dan dilakukan post-test sebagai evaluasi dari hasi pengabdian masyarakat ini. Kemudian data diuji menggunakan Paired Samples Test. (NOTOADMOJO SOEKIDJO, 2012)

Tabel 4.1

Pentingnya Pemberian ASI EKslusif

\begin{tabular}{|c|c|r|r|l|}
\hline Variabel & $\mathbf{N}$ & Mean & $\begin{array}{c}\text { Std. } \\
\text { Deviation }\end{array}$ & $\mathbf{a}=\mathbf{0 , 0 5}$ \\
\hline Pre-Test & 50 & 58.8000 & 15.86165 & \multirow{2}{*}{$\rho=0,000$} \\
\hline Post-Test & 50 & 76.4000 & 11.91124 & \\
\hline
\end{tabular}

Dari hasil olahan data menggunakan uji Paired Samples Test dengan jumlah sampel 50 orang diperoleh ada peningkatan pengetahuan dari rata-rata nilai quisioner pre-test diperoleh nilai jawaban yang benar 58,88 setelah penyuluhan berubah menjadi 76,40 dengan nilai $\rho=0.000$ yang berarti terjadi peningkatan pengetahuan pada ibu terkait pentingnya pemberian ASI Eklusif pada bayi mereka.

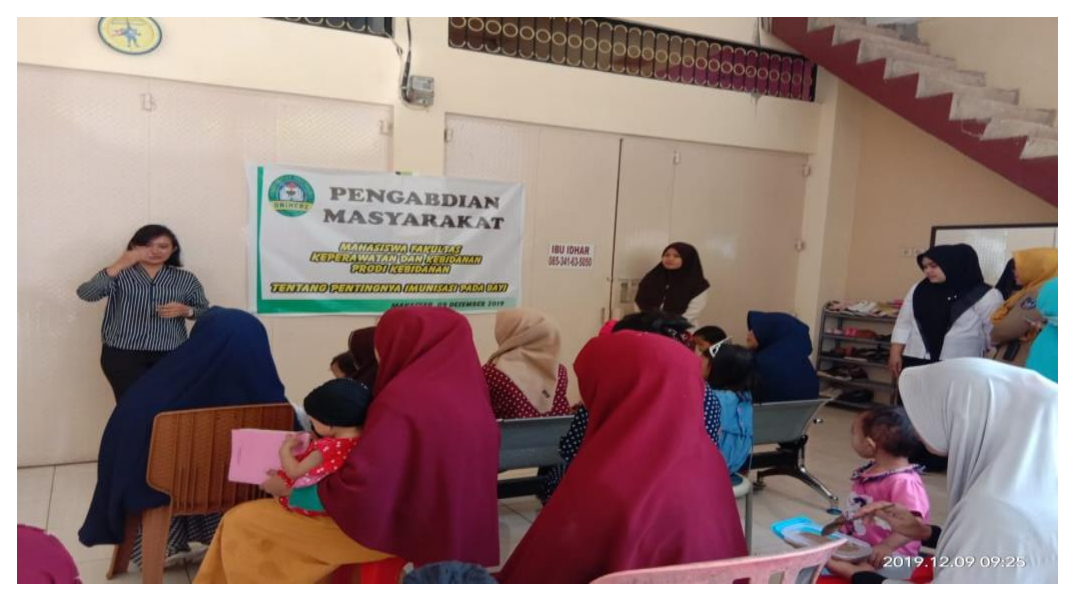

Gambar 4.1 Foto Kegiatan Penyuluhan 


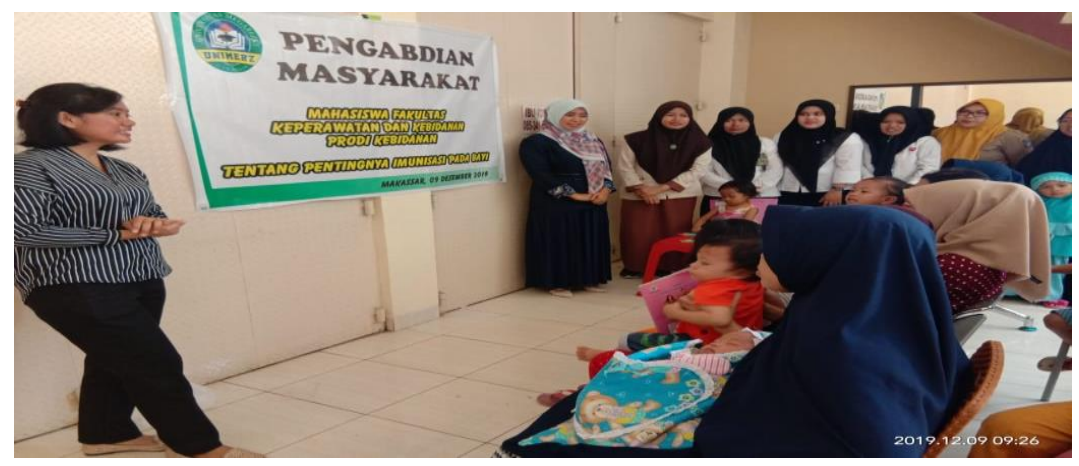

Gambar 4.2 Foto Kegiatan Penyuluhan

\section{KESIMPULAN}

Penyuluhan yang dilakukan di Puskesmas Minasaupa diperoleh hasil dengan menggunakan uji Paired Samples Test dengan jumlah sampel 50 orang bahwa ada peningkatan pengetahuan dari rata-rata nilai quisioner pre-test diperoleh nilai jawaban yang benar 58,88 setelah penyuluhan berubah menjadi 76,40 dengan nilai $\rho=0.000$ yang berarti terjadi peningkatan pengetahuan pada ibu terkait pentingnya pemberian ASI Eklusif pada bayi mereka.

\section{DAFTAR PUSTAKA}

Akbulut, H. H. (2010). Hubungan Tingkat Pengetahuan Ibu Tentang Asi Eksklusif Dengan Pemberian Asi Eksklusif Di Desa Harjobinangun Purworejo. Kesmas Jurnal Kesehatan Masyarakat, 9(1), 76-99.

Anam, K., Setiandari, E., \& Handayani, E. (2019). Hubungan Pengetahuan Sikap Ibu Dalam Praktik Pemberian Asi Ekslusif Di Wilayah Kerja Puskesmas Pekapuran Raya Kecamatan Banjarmasin Timur Kota Banjarmasin Tahun 2018. Dinamika Kesehatan Jurnal Kebidanan Dan Keperawatan, 10(2), 675686. Https://Doi.Org/10.33859/Dksm.V10i2.526

Annisa, \& Naimah. (2012). Maternal And Neonatal Health Journal Diterbitkan Oleh: Prodi Kebidanan Malang, Poltekkes Kemenkes Malang. Maternal And Neonatal Health Journal, 1-4.

Badan Ppsdm Kesehatan Informasi Sdm Kesehatan Kementrian Kesehatan Republik Indonesia. (2020). Profil Puskesmas Minasa Upa Kota Makassar. Bppsdmk.

Http://Bppsdmk.Kemkes.Go.Id/Info_Sdmk/Info/Fasyankes?Unit=1070

Bahriyah, F., Jaelani, A. K., \& Putri, M. (2017). Hubungan Pekerjaan Ibu Terhadap Pemberian Asi Eksklusif Pada Bayi. Jurnal Endurance, 2(2), 113.

Dinas Kesehatan Kabupaten Semarang. (2015). Perbedaan Efektivitas Antara Pijat Oksitosin Dan Pijat Payudara Terhadap Involusi Uteri Pada Ibu Post Partum Di Bpm Kota Pematangsiantar. Profil Kesehatan Kab.Semarang, Vii, 8-13.

Notoadmojo Soekidjo. (2012). Metodologi Penelitian Kesehatan (Ed. Rev). Pt Rineka Cipta Jakarta.

Rama. (2017). Puskesmas Minasa Upa Kota Makassaar. Https: / /Pkmminasaupa.Wixsite.Com/Pkmmu

Rosyid, Z. N., \& Sumarmi, S. (2017). Hubungan Antara Pengetahuan Ibu Dan Imd Dengan Praktik Asi Eksklusif. Amerta Nutrition, 1(4), 406. Https: / / Doi.Org/10.20473/Amnt.V1i4.2017.406-414

Simanungkalit, H. M. (2018). Status Pekerjaan Dan Pengetahuan Ibu Menyusui Terhadap Pemberian Asi Eksklusif. Jurnal Info Kesehatan, 16(2), 236-244. Https: / /Doi.Org/10.31965/Infokes.Vol16.Iss2.222 